\title{
The chemical composition of Amazonian plants $\left(^{*}\right)$
}

A Catalogue, edited by Setor de Fitoquimica, INPA, Manaus, Amazonas

FAMILY :

Leguminosae-Papilionatae

OCCURRENCE : Amazônia

SHRUB AND ROOTS:

Rotenon (I)

Deguelin (II)

Tephrosin (III)
SPECIES:

Derris utilis A. C. Smith

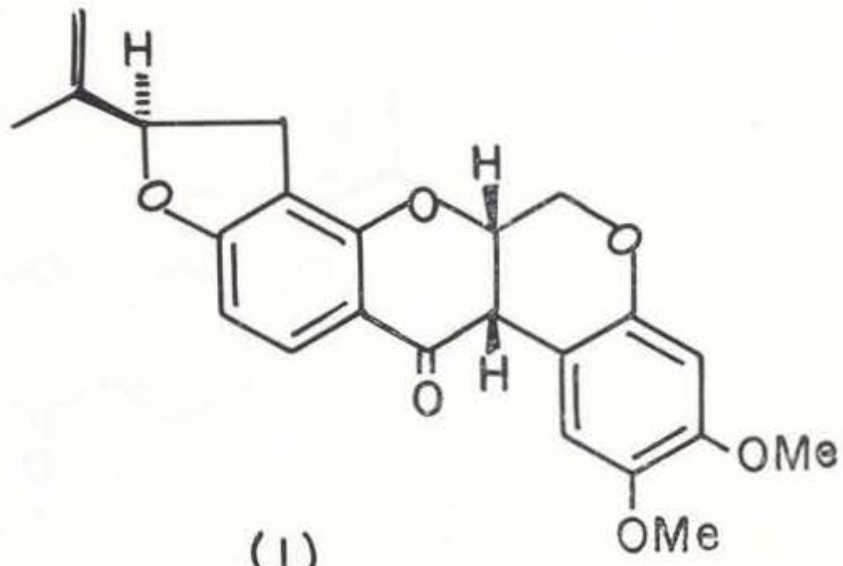

(<smiles>COc1cc2c(cc1C)C1(O)C(=O)c3ccc4c(c3OC1CO2)C=CC(C)(C)O4</smiles>

(III)

REFERENCE :

Clark, E. P. (1931) J. Am. Chem. Soc. 53, 3431; (1932) 54, 4454.

(*) - Contributions to this catalogue, which will be continued in subsequent issues of this Journal, are invited, and should be submitted to address given above. 
FAMILY :

Leguminosae-Papilionatae

OCCURRENCE : Amazônia

TRUNK WOOD AND ROOTS :

Rotenon (I)

Dehidrorotenon (II)
SPECIES :

Derris urucu (Killip et Smith) Macbr.<smiles>C=C(C)[C@H]1Cc2c(ccc3c2O[C@H]2COc4cc(OC)c(OC)cc4[C@H]2C3=O)O1</smiles><smiles>C=C(C)C1Cc2c(ccc3c(=O)c4c(oc23)COc2cc(OC)c(OC)cc2-4)O1</smiles>

REFERENCE :

Kreier, G. R. (1941) Zent. I, 2308.

Braz Filho, R., Gottlieb, O. R., Mourão, A. P. and Sousa Oliveira, F. (1973) unpublished results 192 - 


\section{FAMILY :}

Leguminosae-Papilionatae

OCCURRENCE: Manaus, Amazonas

VINES AND ROOTS :

Derricidin (I)

2',4'-Dihydroxy-3'-prenylchalcone

4'-Hydroxylonchocarpin (II, $\mathrm{R}=\mathrm{OH}$ )

Lonchocarpin (II, $\mathrm{R}=\mathrm{H}$ )

6-Prenyl-5,7-dihydroxyflavanone

4-Prenyl-3,5-dimethoxystilbene (III, $\mathrm{R}=\mathrm{H}$ )

4-Prenyl-3,5,4'-trimethoxystilbene (III, $\mathrm{R}=\mathrm{OMe}$ )
SPECIES :

Derris floribunda (Bth.) Ducke

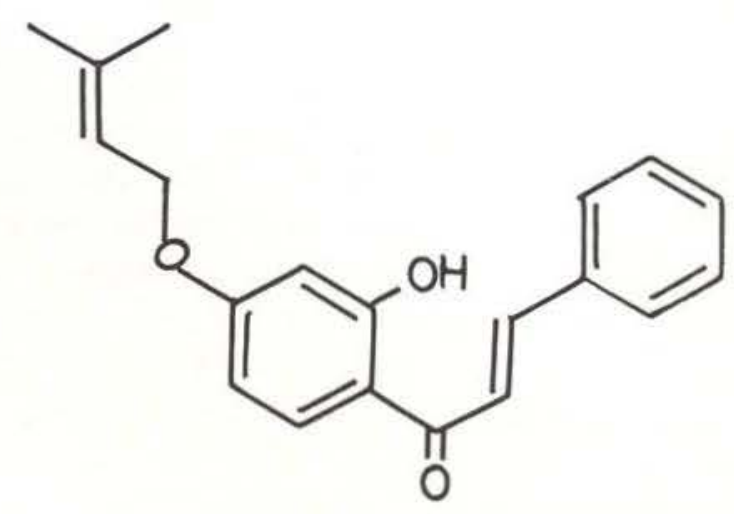

( 1$)$

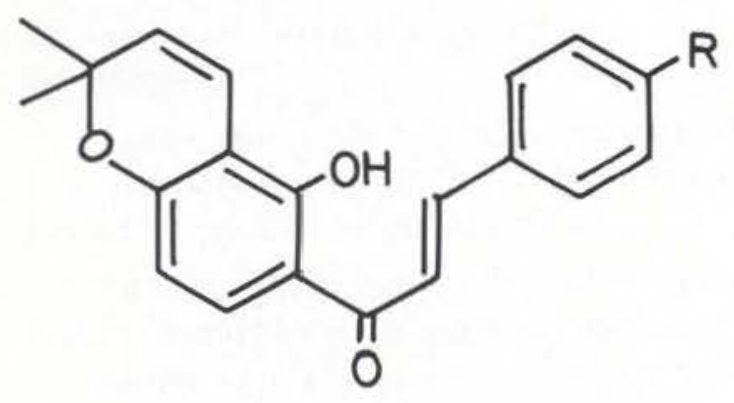

(II)<smiles>[X]Oc1cc(/C=C/c2ccc([R])cc2)cc(OC)c1CC=C(C)C</smiles>

\section{REFĚRENCE :}

Braz Filho, R., Carneiro dos Santos, M., Gottlieb, O. R., Mourão, A. P. and da Rocha, A. I. (1973) unpublished results. 